\title{
Desenvolvimento de Embalagem para Sabonete Vegetal
}

\author{
Development of Packaging for Vegetable Soap \\ CUNHA, Nataly Lima; Graduando; Universidade Federal do Amazonas \\ natalynaty.2015@gmail.com
}

DE SOUZA, Thiago Teixeira; Graduando; Universidade Federal do Amazonas

thiago.jakobu@gmail.com

PACHECO, Karla Mazarelo Maciel; Doutora; Universidade Federal do Amazonas karlamazarelo@hotmail.com

\section{Resumo}

Este artigo descreve sobre a intervenção ergonômica do design em embalagem para sabonetes vegetais glicerinados, fornecida pela empresa 'Cheiro Amazônico', projetada a base de plástico filme transparente e papel envoltório com informações técnicas sobre o produto. $\mathrm{O}$ trabalho faz uma abordagem qualitativa a partir de levantamento bibliográfico, análise de dados e estudo de caso para a identificação de oportunidades e limitações da proposta, vislumbrando melhorias no objeto observado. Dos resultados destacam-se: um estudo de embalagem regional para cosméticos conforme conceitos ergonômicos utilizados por autores especializados; e um produto funcional e visualmente atrativo, com boa aceitação por parte de seus consumidores.

Palavras Chave: embalagem; ergonomia; regional e mercado.

\section{Abstract}

This article describes the ergonomic intervention of the design in packaging for glycerinated vegetable soaps, provided by the company 'Smell Amazon', designed based on transparent plastic film and wrapping paper with technical information about the product. The work makes a qualitative approach based on a bibliographical survey, data analysis and case study, to identify opportunities and limitations of the proposal, looking for improvements in the observed object. Of the results, we highlight: a regional packaging study for cosmetics according to ergonomic concepts used by specialized authors; And a functional and visually attractive product, with good acceptance by its consumers.

Keywords: packing; ergonomics; regional and commerce.

\section{Introdução}

O presente trabalho trata-se do resultado de algumas ações realizadas sob os conceitos e técnicas orientadas pela disciplina de Estudo de Embalagem ofertada pelo Departamento de Design e Expressão Gráfica da Universidade Federal do Amazonas, que busca fazer um contato direto entre três elementos importantes: aluno, produto e mercado e como considerar as necessidades do cliente/consumidor. Sobre esse princípio, os acadêmicos de design vinculados à referida disciplina têm como desafio identificar uma empresa que trabalha com produtos de 
embalagem e a ela oferecer melhorias relacionadas a atributos do design como a forma, a função e, principalmente, a intervenção ergonômica da sua embalagem. Para atender esse requisito, foi realizado um estudo de caso com uma empresa de representatividade regional que atende por nome 'Cheiro Amazônico', um estabelecimento comercial localizado no bairro Adrianópolis na cidade de Manaus, que produz e vende produtos do tipo sabonetes vegetais glicerinados, sabonetes esfoliantes com bucha vegetal, sabonetes líquidos e outros.

Com a experiência adquirida durante o estudo, foi-se percebido que a embalagem desempenha um fator crucial. Ela se torna a mediadora entre o consumidor e o produto, podendo convencer ou não baseada na relação forma, cores e funcionalidade.

Neste contexto, o trabalho ergonômico centrou-se em uma embalagem para sabonetes glicerinado, fornecida pela empresa em questão, no qual foram verificados os problemas e as possíveis soluções para a melhoria do referido produto ao mercado de cosméticos amazonense, razão pela qual se encontra centralizado nos seguintes objetivos:

- Conhecer sobre a empresa de cosmético fornecedora do objeto de estudo;

- Observar o tipo de embalagem (produto) produzida pela empresa e os atributos do design nela inseridos;

- Identificar o perfil dos consumidores;

- Desenvolver um protótipo com base nas informações estudas pela pesquisa;

\section{Metodologia}

O estudo apresenta uma abordagem qualitativa, com objetivos de caráter exploratório e descritivo (GIL, 2002). A estrutura do conteúdo contempla uma pesquisa do tipo bibliográfica e documental, ratificada em um estudo de caso específico - correlacionado aos processos de inovação e de estratégia (YIN, 2001).

O contato realizado com a empresa de estudo 'Cheiro Amazônico' procedeu da seguinte forma: através de conversa com a Déborah Laredo (filha da dona) durante a Feira de Artesanato da Eduardo Ribeiro. Ela foi informada sobre o projeto e foi questionada a possibilidade de se fazer uma embalagem para o seu produto, com a qual entrou em concordância. A partir daí, o contato e troca de informações foram feitos através de mensagens, e-mails e visitas ao ponto de venda.

$\mathrm{O}$ acesso aos tipos de embalagens fornecidos pela empresa foi feito através da compra dos produtos com as embalagens escolhidas. Para identificar o perfil dos consumidores, foi realizado um checklist do consumidor. A partir dos problemas identificados, como a questão da escolha do material, relação com o usuário e o layout da embalagem, foi definida a seguinte estratégia: trabalhar o layout da embalagem para que provoque fortes reações emocionais e desenvolver uma estrutura firme e resistente com um material que passe a sensação de segurança no uso em meio à água, considerando o armazenamento após o primeiro uso.

Sendo assim, o trabalho foi desenvolvido com base no método de Lincoln Seragini, um dos especialistas e pioneiros em embalagem no Brasil. O seu método é composto de sete estágios: 1. Identificação do tipo de desenvolvimento; 2. Planejamento preliminar; 3. Desenvolvimento estrutural; 4. Desenvolvimento formal gráfico; 5. Implantação; 6. Embalagem operando e; 7. Avaliação e correção de falhas.

Todo o trabalho foi desenvolvido dentro de um prazo de 3 meses começando em março e finalizando em julho de 2017, com o assessoramento da disciplina acadêmica Estudo de Embalagem ministrada nas dependências do Departamento de Design e Expressão Gráfica da Universidade Federal do Amazonas. 


\section{GAMPI plural ${ }^{47}$}

\section{A Empresa (Estudo de caso 1)}

Conforme dito anteriormente, a empresa escolhida foi a Cheiro Amazônico (Figura 1) que atua no mercado desde 2005. A missão estabelecida pela empresa é fornecer aos seus clientes produtos de caráter regional produzidos artesanalmente, tendo como visão ser referência no ramo de cosméticos e perfumarias produzidos artesanalmente e, como lema, mostrar através de seus produtos um pouco da riqueza dos extratos e óleos essenciais da natureza Amazônica. A empresa é familiar e quem é registrada como dona da empresa é Monica Meneguzzi, com a ajuda das duas filhas e a irmã administram a empresa.

Os seus produtos são produzidos artesanalmente no bairro Adrianópolis, Manaus, AM. No entanto, seu ponto de venda (Figura 2) é na Feira de Artesanato da Eduardo Ribeiro, no Centro. Mas os produtos também são revendidos em lojas como a Loja Tupiniquim, localizada no Aeroporto Internacional Eduardo Gomes.

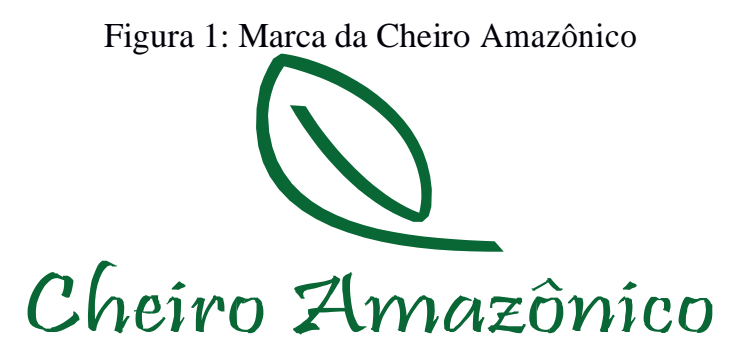

Fonte: Monica Meneguzzi (dona da empresa)

Figura 2: Pontos de venda da Cheiro Amazônico

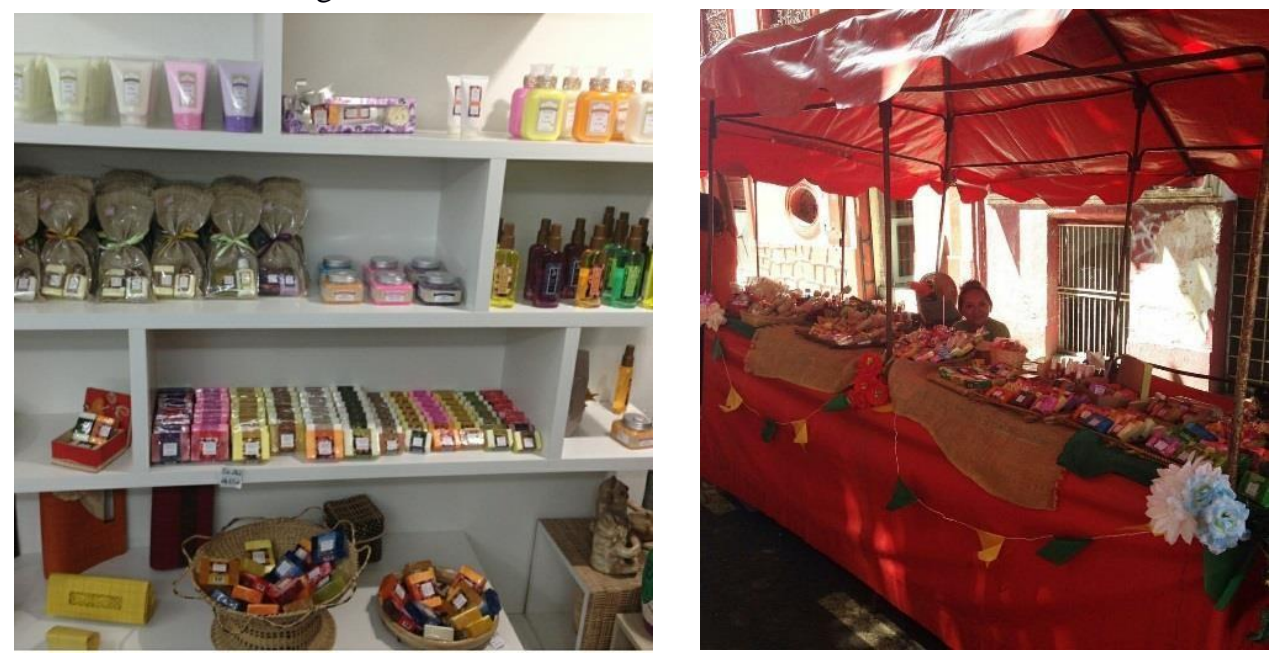

Fonte: Imagens fornecidas pela empresa de estudo

Seus produtos possuem propriedades adstringentes, emolientes, hidratantes, suavizantes e calmantes. A produção é composta principalmente por (Figura 3) sabonetes vegetais glicerinados ou sabonetes esfoliantes com bucha vegetal, sabonetes líquidos, hidratantes, óleos corporais, esfoliantes corporais, aromatizadores de ambientes, perfumes e outros. Devido à empresa trabalhar com diversos produtos, foi sugerido focar-se somente em um produto: o sabonete vegetal glicerinado em barra, escolhido por ter a embalagem mais problemática. 


\section{GAMPI}

Figura 3: Produtos produzidos pela Cheiro Amazônico
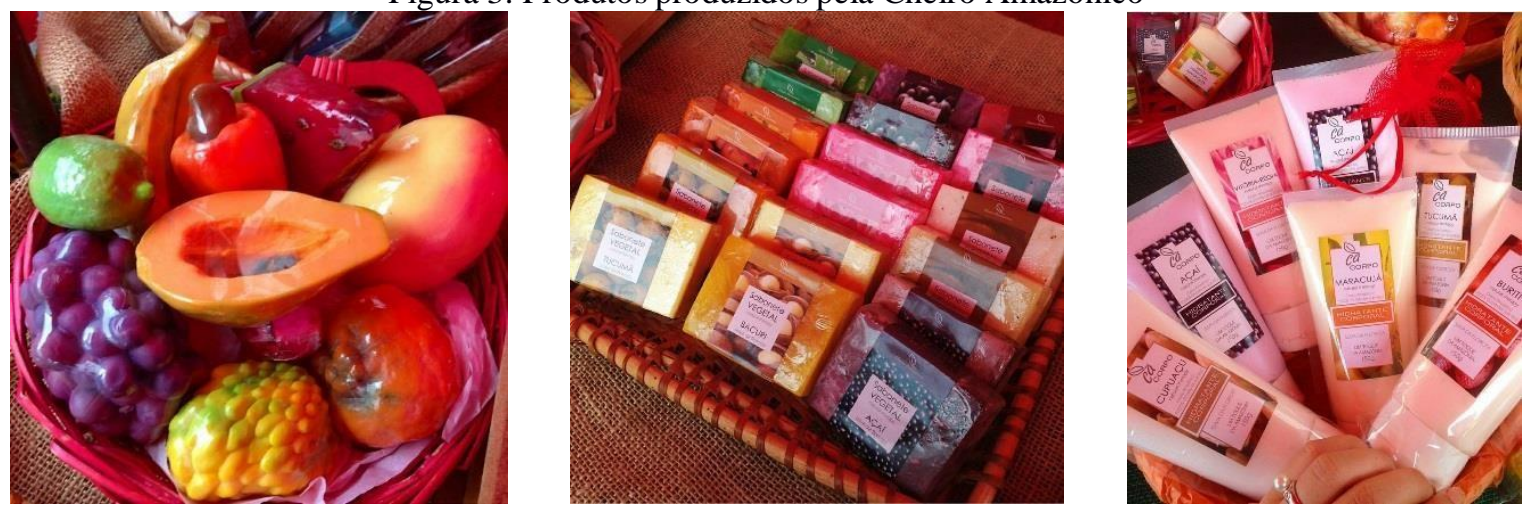

Fonte: Imagens fornecidas pela empresa de estudo

\section{O Produto e seu mercado (Estudo de caso 2)}

Segundo as pesquisas do mercado referentes à intervenção do design sobre a embalagem, constatou-se que o mercado atual de produtos de higiene pessoal e banho no Brasil vem demonstrando um crescimento mais elevado do que outros mercados que tradicionalmente possuem mais investimentos. Os dados coletados pelo Serviço Brasileiro de Apoio às Micros e Pequenas Empresas - SEBRAE (2015) e pela ABIHPEC (ASSOCIAÇÃO BRASILEIRA DA INDÚSTRIA DE HIGIENE PESSOAL, PERFUMARIA E COSMÉTICOS, 2016), acusam que o mercado brasileiro de produtos para banho movimentou em torno de $\mathrm{R} \$ 2,65$ bilhões no ano de 2009 , em 2013 passou para $\mathrm{R} \$ 5,10$ bilhões e com a expectativa que alcance o patamar de $\mathrm{R} \$ 7$ bilhões em 2018, apesar da crise político- financeira que o país passou em 2014. Tais dados demonstram um crescimento que anima investidores e atrai o produtor individual, como a escolhida para o estudo.

Com isso, o sabonete vegetal no formato em barra (Figura 4) é feito a partir de diversos materiais regionais, possuindo cores e cheiros diversos e diferenciados (Figura 5) devido à variedade de matérias-primas, além de diversos tamanhos (120g e 60g). No entanto, o material e a forma da embalagem o desvalorizam, coberta somente por um filme plástico transparente, que por sua vez é envolto com uma faixa de papel que contém informações visuais sobre o sabonete, como quem fabrica, do que é feito, modo de uso e demais informações obrigatórias.

Se o produto deve satisfazer os desejos e necessidades do consumidor, a embalagem cumpre esse papel, na medida em que ela envolve o produto, pode dar "personalidade" a ele, com algum sinal que o identifique e diferencie dos concorrentes e, ainda, por meio dela, podemos conseguir a melhor utilização do produto envasado (NEGRÃO, CAMARGO, 2009, p.105 e 106).

Sendo assim, o maior problema está no pós-uso do sabonete. Após a sua abertura, a embalagem não tem como ser fechada devido ao rompimento do plástico ou o seu amassamento, o que não permite a sua reutilização após aberto. Além disso, existe o problema de manuseio durante o banho, dificultado pela embalagem, fazendo com que o usuário seja obrigado a comprar uma saboneteira para guardar o sabonete. 
Fonte: Fonte: Imagem fornecida pela empresa de estudo

Figura 5: Sabonetes na Feira de Artesanato da Eduardo Ribeiro

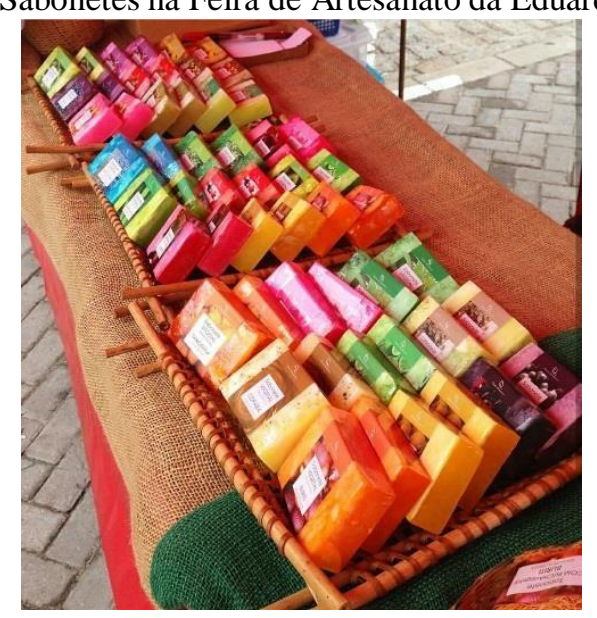

Fonte: Imagem fornecida pela empresa de estudo

\section{O Consumidor (Estudo de caso 3 )}

Para a análise dos consumidores foi feita um checklist do consumidor que envolve os seguintes tópicos: 1. Identificação (Quem é/qualificação, Sexo, Idade, Classe de renda); 2. Hábitos e atitudes (Como compra, Por que comprar, Como se comporta em relação à categoria do produto) e; 3. Tentar descobrir (Por que compraria nosso produto), (MESTRINER, 2002a, pag. 29).

A partir desse checklist, foi constatado que são de qualquer classe, mas com maior foco nas classes B e C. São jovens, adultos e idosos de ambos os sexos, majoritariamente mulheres. São pessoas que apreciam sabonetes com cheiro diferenciados e que valorizam a qualidade e personalidade atribuídos.

- Appropriate and vivid picture or packaging color, which delivers them a happy feeling, or an easy handle/open/dose/dispose, package shape. All these elements contribute each important effort to catch consumer's attention and interest. Besides each element's single function, we think that a good combination of these elements may lead the product more eye-catching and attractive.

> Analyzing an importance of its separate elements for consumer's choice reveals the impact of packaging and its elements on consumer's purchase decision. For this purpose, main package's elements has been identified: graphic, color, size, 
form, and material of packaging are considered, wrapper design, innovation while product information, producer, country-of-origin and brand are considered as important ones. Moreover, the impact of package elements on consumers purchase decisions has been evaluated, and it is concluded that it depends on the consumer's involvement level, time pressure or individual characteristics of consumers.

$>\quad$ It has also revealed that elements of packaging are the most important for consumer's purchase decision. For a major part of consumers' attraction was a size of package and material are the main visual elements, whereas, product information is also the main verbal elements when purchasing milk and washingpowder. (AHMED, PARMAR, AMIN, 2014, p.10)

Para esses consumidores, o produto oferece a oportunidade de consumir um sabonete diferenciado, com personalidade única, cheiros e texturas singulares. O consumidor compra esse produto porque busca algo único, sendo assim ele tende a experimentar a diversidade que o mesmo apresenta, pois ele se identifica com o que está sendo exposto.

\section{Concorrentes e análise da embalagem (Estudo de caso 4)}

No local (Feira de Artesanato da Eduardo Ribeiro) em que está situado o ponto de venda da Cheiro Amazônico, o líder de vendas é a Harmonia Nativa (Figura 6), com um estande que possui mais apelo visual, com a marca mais bem trabalhada nas embalagens e entornos. As mesmas características foram percebidas nos demais concorrentes, mas em menor escala.

Sendo assim, os produtos com menor destaque visual são os da Cheiro Amazônico juntamente com a Amhy (Figura 7) e Amazon (Figura 8), que também não possuem uma embalagem muito desenvolvida na questão da escolha do material. Essa diferença nas embalagens influência diretamente no preço dos sabonetes como exemplificada na Tabela 1.

Tabela 1: Comparação de preços dos sabonetes

\begin{tabular}{ccc} 
& $\begin{array}{c}\text { SABONETE } \\
\text { VEGETAL }\end{array}$ & $\begin{array}{c}\text { CONJUNTO DE } \\
\text { SABONETES }\end{array}$ \\
\hline CHEIRO AMAZÔNICO & $\mathbf{R} \$ 7,00$ & $\mathbf{R} \$ 10,0$ \\
\hline HARMONIA NATIVA & $\mathbf{R} \$ \mathbf{1 2 , 0}$ & $\mathbf{R} \$ 10,0$ \\
\hline AMAZON & $\mathbf{R} \$ \mathbf{1 0 , 0}$ & $\mathbf{R} \$ 15,0$ \\
\hline AMHY & $\mathbf{R} \$ 6,00$ & $\mathbf{R} \$ 10,0$ \\
\hline
\end{tabular}

Figura 6: Sabonete da Harmonia Nativa

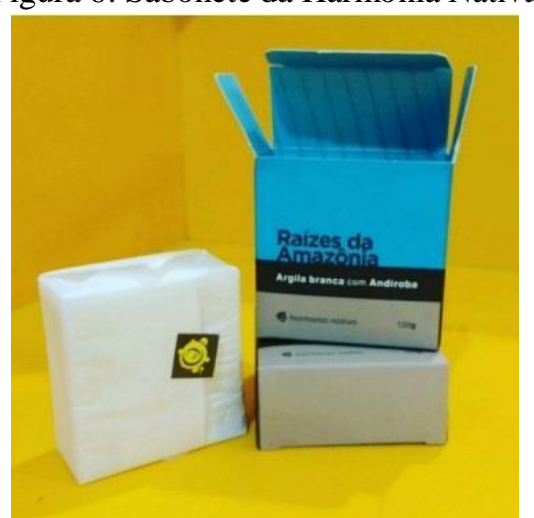

Fonte: Rede social instagram (@harmonianativa_amshopping) 


\section{plural $^{\text {GA }}$}

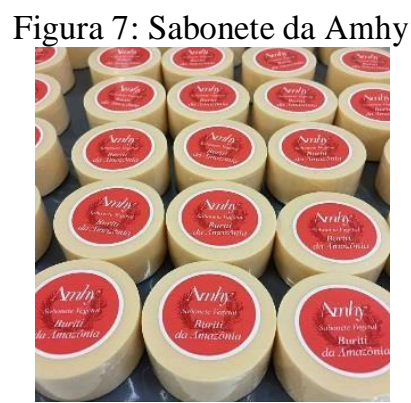

Fonte: Rede social instagram (@ amhyperfumariaecosmeticos)

Figura 8: Sabonete da Amazon Velas e Sabonetes

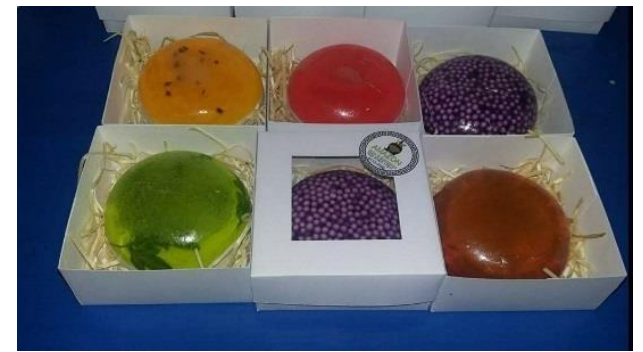

Fonte: Rede social facebook (@amazonvelasesabonetes)

As análises feitas a seguir (Tabela 2 e Tabela 3) foram com base em um formulário de estudo de campo (informações objetivas, linguagem visual da categoria, informações subjetivas), um checklist mercadológico e um checklist técnico (NEGRÃO, CAMARGO, 2009). A partir das informações coletadas, foram feitas as análises quanto aos elementos visuais e estrutura física da embalagem com a sua concorrente mais forte, a Harmonia Nativa, para evidenciar os problemas da embalagem a serem trabalhadas e também para desenvolvimento das partes em que a nova embalagem pode se destacar e diferenciar nesse mercado.

Ergonomic design results in a product that is comfortable to use and that is unlikely to give rise to any cause of accident, injury or discomfort, such as the occurrence of repetitive strain injury, for instance.

Ergonomics therefore relates to how people interact with physical objects and seeks to improve the design of products in order to make such interactions more comfortable and to optimise both health and productivity. In terms of packaging, designers frequently apply ergonomic principles in order to produce a more harmonious interaction between products and the human body (AMBROSE, HARRIS, 2011, p.142).

Tabela 2: Análise dos elementos visuais das embalagens

\begin{tabular}{|c|c|c|}
\hline & $\begin{array}{c}\text { CLIENTE } \\
\text { (Cheiro Amazônico) }\end{array}$ & $\begin{array}{c}\text { LÍDER } \\
\text { (Harmonia Nativa) }\end{array}$ \\
\hline FORMA & Retangular & Quadrada \\
\hline \multirow[t]{2}{*}{ COR } & $\begin{array}{l}\text { Varia de acordo com o tipo da } \\
\text { matéria-prima. }\end{array}$ & $\begin{array}{l}\text { Varia de acordo com o tipo da } \\
\text { matéria-prima. }\end{array}$ \\
\hline & $\begin{array}{l}\text { A marca, que é composta pelo } \\
\text { nome da empresa e o símbolo de } \\
\text { uma folha, está localizada no } \\
\text { topo em tamanho reduzido (sem } \\
\text { destaque). A mesma é } \\
\text { minimalista e transmiti que tudo }\end{array}$ & $\begin{array}{l}\text { A marca, que é composta pelo } \\
\text { nome da empresa e um símbolo, } \\
\text { está localizada no canto inferior } \\
\text { esquerdo. A mesma é } \\
\text { minimalista e transmiti que os } \\
\text { produtos são orgânicos e }\end{array}$ \\
\hline
\end{tabular}



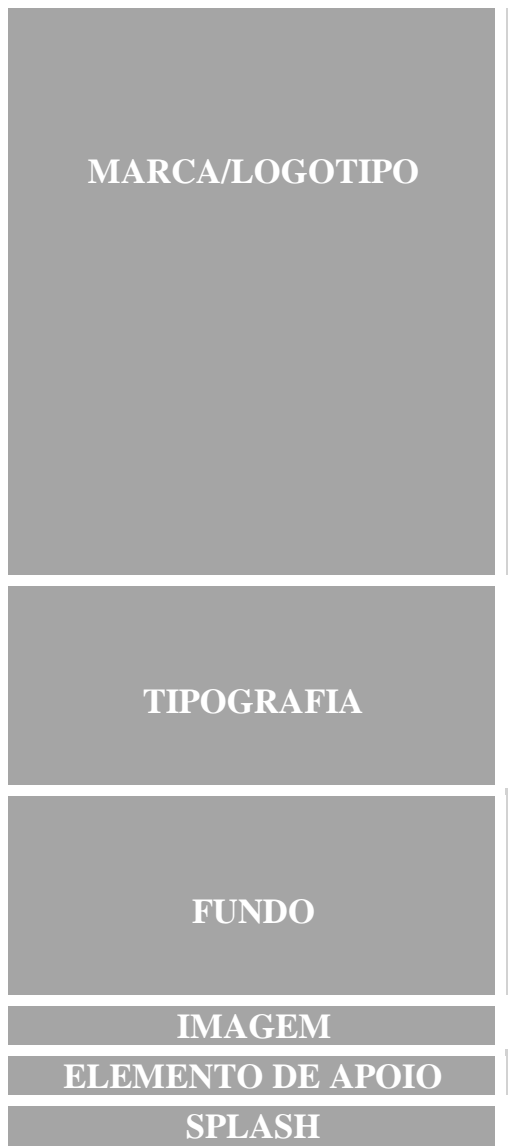

TIPOGRAFIA

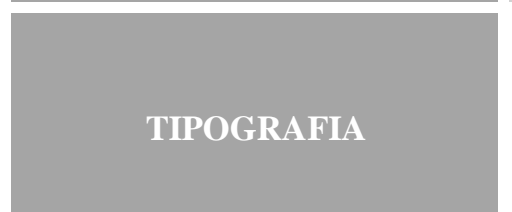

o que é produzido é natural, pois a sua matéria prima tem como origem, a floresta.

Quanto ao logotipo da linha "Seiva da Floresta" a mesma não possui, está em fonte reduzida sem destaque com uma tipografia qualquer. naturais.

Quanto ao logotipo da linha "Raízes da Amazônia" a tipografia escolhida foi uma de traços grosso e retos com o intuito de chamar a atenção, pois a mesma está em destaque.
Possui duas tipografias: uma com a fonte maior para informar o que é e do que é. A outra com a fonte menor informa a linha do produto e que é terapêutico.

Possui a imagem da matériaprima e a cor é correspondente a mesma.
Possui uma tipografia, o que varia é o tamanho da fonte sendo: a maior para informar a linha e a menor para informar do que é.

São três listras de tamanhos diferentes que variam por importância e por tonalidade de uma cor que muda de acordo com a matéria-prima.

\begin{tabular}{c|c|}
\hline Imagem da matéria-prima & Não possui \\
\hline Não possui & Não possui \\
\hline Não possui & Não possui \\
\hline
\end{tabular}

Fonte: Dos autores

Tabela 3: Análise da estrutura física das embalagens

\begin{tabular}{|c|c|c|}
\hline & $\begin{array}{c}\text { CLIENTE } \\
\text { (cheiro amazônico) }\end{array}$ & $\begin{array}{c}\text { LílDER } \\
\text { (harmonia nativa) }\end{array}$ \\
\hline MATERIA-PRIMA & Plástico e celulose. & Cartão (semirrígido) \\
\hline TIPOLOGIA & Envoltório e papel. & Caixa. \\
\hline
\end{tabular}

Fonte: Dos autores

A seguir, temos a análise da embalagem da Cheiro Amazônico do ponto de vista de como seus elementos estão distribuídos e sua configuração quanto a tamanho, textura, contraste, plano, posição no espaço e tensão espacial conforme exemplificado em: (Figura 9, Figura 10, Figura 11 e Tabela 4)

Figura 9: Identificação de elementos que compõe a embalagem

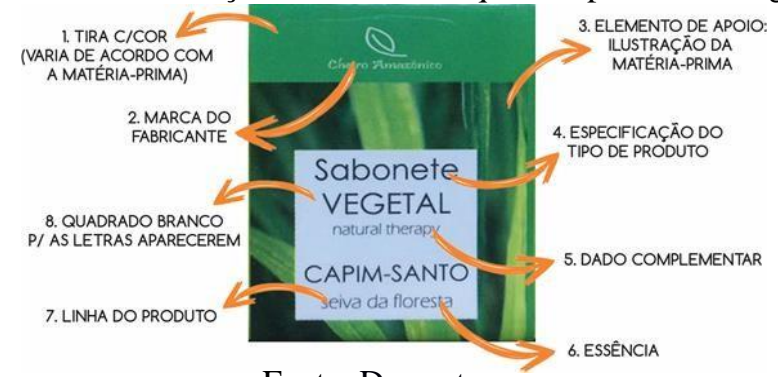

Fonte: Dos autores

6o GAMPI Plural, 2017, Joinville, SC. 
Figura 10: Distribuição dos elementos no grid

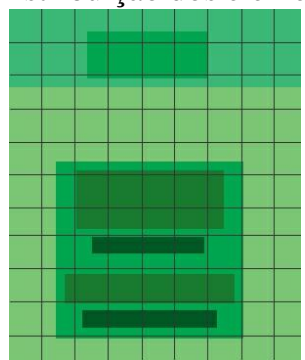

Fonte: Dos autores

Figura 11: Configuração do papel envoltório

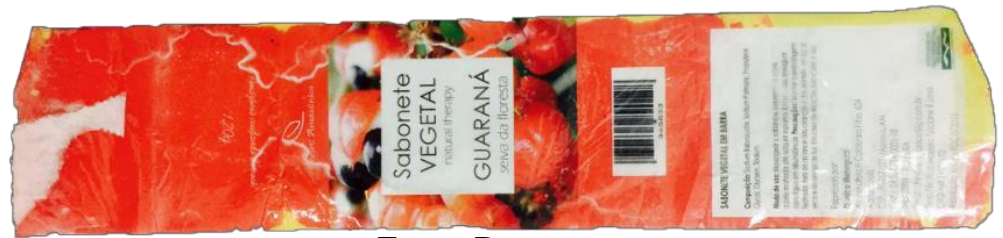

Fonte: Dos autores

Tabela 4: Análise formal da embalagem

Comprimento: $7 \mathrm{~cm}$, Largura: $4 \mathrm{~cm}$, Sistema de impressão:

TAMANHO OFFSET

Não há, pois tudo é somente de uma cor.

CONSTRASTE

O que predomina é a fotografia, mas que perde o foco devido ser da mesma os que as demais.

As demais informações têm sua pregnância prejudicada.

A profundidade aparece devido a sobreposição dos
elementos. Tendo o elemento 3 como fundo, depois o 1 e o 8
e assim por diante.

\section{POSIÇÃO NO ESPAÇO}

A direção da leitura é vertical.

Há sobreposição entre os elementos 8 e 4-7, 3 e 8.

Há um intervalo médio entre os elementos 1,8 e 7 .

Há um intervalo pequeno entre os elementos 4 e 5, 6 e 7.
Há uma alta tensão entre os elementos centrais que estão sobre postos.

Há muita concentração de informações no centro.

\section{Fonte: Dos autores}

Portanto, pode-se concluir através dessas análises que além do problema com a escolha do material há também a questão da organização dos elementos informativos que compõem a embalagem. 


\section{GAMPI
plurallt}

\section{Estratégia, metas e similares}

Conforme Mestriner (2002a, p.32), "o bom design de embalagem é aquele que responde positivamente aos fatores críticos, como proteção, armazenamento e transporte (...) chamando a atenção do consumidor e despertando o desejo de compra". Seguindo esses preceitos, foi definida a seguinte estratégia: chamar mais atenção pelo apelo visual, provocando fortes reações emocionais e a sensação de segurança no uso por meio de uma estrutura firme e resistente da embalagem utilizada em meio à água, considerando o armazenamento após o primeiro uso.

Com isso em mente, foram estabelecidas as seguintes metas:

$\checkmark$ Colocar no mercado um produto único;

$\checkmark$ Solidificar a marca da empresa no mercado;

$\checkmark$ Mostrar ao consumidor sua qualidade e singularidade;

$\checkmark$ Através do apelo visual (cor, tipografia e forma) provocar fortes reações mocionais;

$\checkmark$ Por meio da escolha do material transmitir a sensação de segurança no uso

através de uma estrutura firme e resistente em meio à água;

$\checkmark$ Possuir traços regionais.

Por conseguinte, foram pesquisadas embalagens similares que expressassem cada uma dessas características: forma remeter a marca, mudança de cor conforme a essência, possuir vitrine para exposição do produto, reutilização da embalagem como saboneteira (influenciando a escolha do material) e apelo visual.

\section{Resultado Projetual}

Por fim, chegou-se ao resultado final com os protótipos e tudo o que foi levantado como pesquisas de mercado, concorrentes, análises e similares implementados na hora de escolher a forma, cor, material e tipografia. Quanto aos protótipos, as embalagens foram produzidas para os sabonetes de uma unidade de $120 \mathrm{~g}$, conjunto de duas unidades de $60 \mathrm{~g}$ e conjunto de quatro unidades de $60 \mathrm{~g}$.

Segundo Camargo e Negrão (2009, p. 172) "a forma e a cor são a base da comunicação visual. Por intermédio destes elementos obtemos: impacto, legibilidade, ilusão de óptica (volume, leveza etc.), distinção e identificação de categoria de produtos etc.". Para que a embalagem carregasse tais características, ela foi projetada do seguinte modo:

Figura 12: Frente e costa da embalagem para 1 unidade de $120 \mathrm{~g}$ e seu manuseio

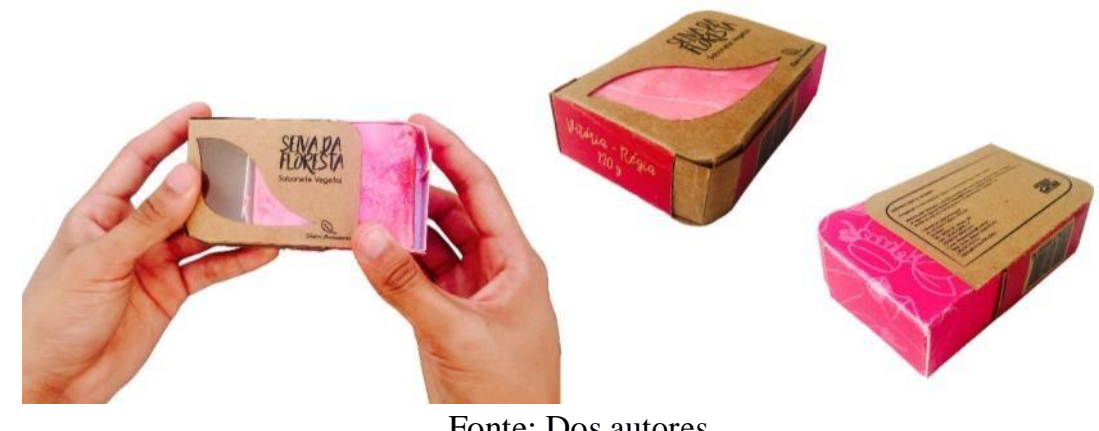

Fonte: Dos autores

Para embalagens unitária e de dupla essência, conforme vistas na Figura 12 e 13, o formato delas fazem alusão a uma folha para serem associadas primeiramente a marca, uma 


\section{GAMPI \\ plural ${ }^{17}$}

univille

folha, mas também à floresta, para haver uma melhor associação entre a marca e o produto.

Figura 13: Frente e costa da embalagem para 2 unidades de $60 \mathrm{~g}$ e seu manuseio
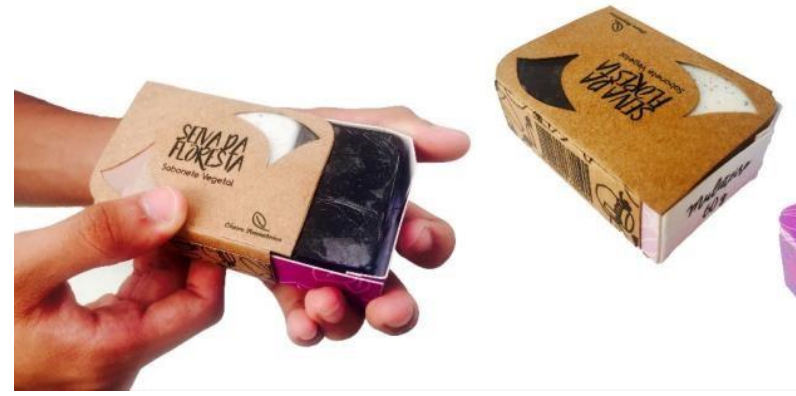

Fonte: Dos autores

Para diferenciar as essências, foram aplicados elementos distintos; a primeira embalagem possui abertura de gaveta para apenas um dos sentidos e uma vitrine em formato de folha; a segunda, por possuir duas essências no mesmo conjunto, possui duas vitrines e possibilidade de ser aberta nos dois sentidos. Já a cor varia de acordo com a essência para que o consumidor possa associar com determinada essência. A estampa escolhida foi algo que remetesse ao artesanal, como os sabonetes são feitos.

Figura 14: Frente e costa da embalagem para 4 unidades de $60 \mathrm{~g}$ e seu manuseio

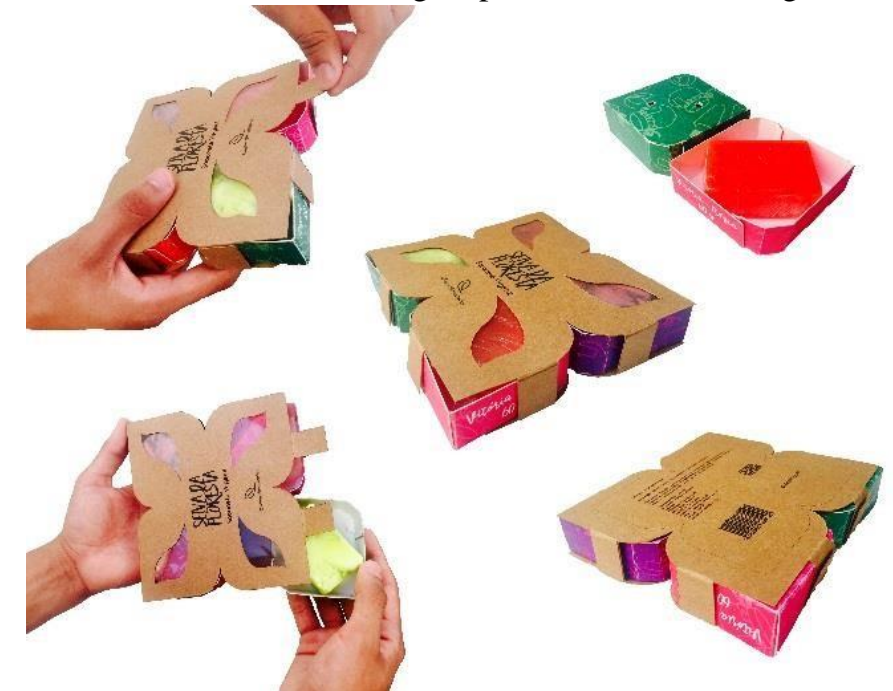

Fonte: Dos autores

Quanto à embalagem para conjunto de quatro sabonetes (Figura 14), foi escolhida uma flor de quatro pétalas para expor as distintas essências, com sua abertura lacrada e com compartimentos individuais para cada sabonete. Para o uso deles, é preciso apenas o destaque da embalagem secundária, unida por colagem simples.

No entanto, para diferenciar os tipos de essências entre as pétalas da flor, foi desenvolvido uma vitrine que permite uma rápida visualização do que há dentro, juntamente com a cor característica de cada essência e o nome da correspondente da mesma escrita na lateral da embalagem primária.

Quanto ao material, foram utilizados três tipos: o Kraft $300 \mathrm{~g}$ para o envoltório dos compartimentos, por possuir um aspecto rústico, combinando com sua natureza artesanal; o 
acetato, para a vitrine e, por fim, o papel branqueado, por ter maior resistência contra a umidade para contato direto com o sabonete. De acordo com Mestriner (2002b, p. 57), "o nome do produto tem tanta importância quanto o nome de uma pessoa tem para a vida em sociedade. Ele distingue o produto dos demais, afirmando sua personalidade" a tipografia utilizada foi a "Beauty and the Beast", como logotipo do nome da linha "Seiva da Floresta", tendo sido escolhida por lembrar os traços irregulares que são feitos nas seringueiras para extração do látex.

Com essa embalagem, é proposto ao consumidor utilizá-la também como saboneteira, isso sendo possível com o material escolhido, possuindo em seu fundo dos compartimentos 2 (dois) furos para o escoamento da água. Além dessa característica, espera-se que com os elementos visuais se crie um vínculo, evitando o seu descarte precipitado, diminuindo impactos ambientais gerados pelos resíduos. Portanto, com a junção de todos esses elementos, pôde-se solucionar o principal problema da embalagem atual que é a sua reutilização após aberta.

\section{Referências}

AHMED, Rizwan Raheem, PARMAR, Vishnu, AMIN, Muhammad Ahmed. Impact of Product Packaging on Consumer's Buying Behavior. In: European Journal of Scientific Research, 2014.

AMBROSE, Gavin, HARRIS, Paul. Packaging the Brand: packaging design and brand identity. Singapore: Ed. AVA Book Production, 2011.

ASSOCIAÇÃO BRASILEIRA DA INDÚSTRIA DE HIGIENE PESSOAL, PERFUMARIA E COSMÉTICOS. Panorama do Setor 2016. In: ABIHPEC, 2016 (https://abihpec.org.br/publicacao/panorama-do-setor-2016-2/). Acesso em 11 jun. de 2017.

GIL, Antonio Carlos. Como Elaborar Projetos de Pesquisa. Metodologia da Pesquisa. 4.ed. São Paulo: Atlas, 2002.

MESTRINER, Fábio. Design De Embalagem - Curso Básico. 2.ed. São Paulo: Ed. Makron Books, 2002a.

MESTRINER, Fábio. Design De Embalagem - Curso Avançado. 2.ed. São Paulo: Ed. Makron Books, 2002b.

NEGRÃO, Celso, CAMARGO, Eleide. Design De Embalagem: do marketing a produção. São Paulo: Ed.Novatec, 2009.

SEBRAE/MG. Como montar uma fábrica de sabonetes artesanais. In: SEBRAE MG, 2015.(https://www.sebraemg.com.br/atendimento/bibliotecadigital/documento/CartilhaManua 1-ou-Livro/Como-montar-uma-Fabrica-de-Sabonetes-Artesanais). Acesso em 22 jun. de 2017.

YIN, Robert K. Estudo de caso: planejamento e métodos. Tradução Daniel Grassi. 2.ed. Porto Alegre: Bookman, 2001. 